\title{
Intercultural learning supported by technology: a small-scale systematic review
}

\author{
Wayan Sintawati ${ }^{\mathrm{a}, 1}$ \\ ${ }^{a}$ Nanjing Normal University, China \\ ${ }^{1}$ wayansintawati@gmail.com \\ * corresponding author
}

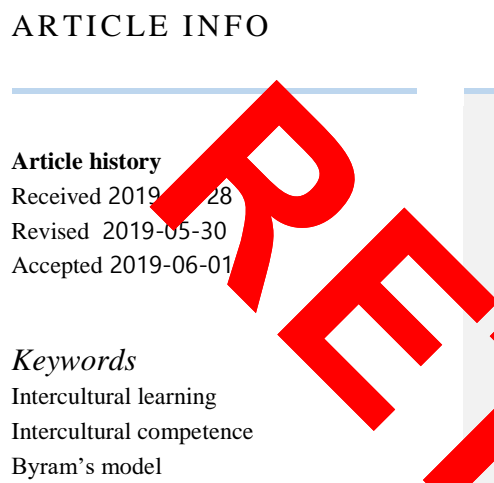

ABSTRACT

\section{Introduction}

Intercultural interaction and communication are rapidly increasing throughout the world. In a fast-growing and globalized world, the ability to communicate with people across cultures is very important. This study discusses describing the Byram model of the environment used in learning, culture, language, and problems and solutions for the future and using qualitative methods by following the pattern of previous search with the main sources from Google Scholar, Baidu Scholar,

Intercultural competence nce Direct and Mendeley's search platform. The result from this a h is (1) This ICC model can be used as a good reference and sidernn for teacher planning in discussions and discussions to develop IC sty (2) Inter-cultural learning is more effective and more imp ive h as Holograms, VR technology, Artificial Intelligence, $c^{\prime}$ The most widely used topics in the studio are culture $(\mathrm{n}=$ 4, daily $(\mathrm{n}=2)$, controversial issues, language, communication, physic space me resolution), resolution, resolution, and stereo ping lems, solutions, and suggestions for future studies and prac of the problems that most of us find here are socialisation. I flution to this problem is to familiarise students with this communica

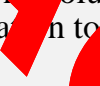

Among the Millennials, also known as Generation Y, int iltural iteraction and communication rapidly increase in whole the world. The world in the era alization requires the ability to communicate effectively and efficiently with people across cultures is very important. Ensuring that students in the school get intercultural communication skills that are effective and in accordance with what is needed today. this ability is an important ability that must be possessed by every student [1]. Intercultural communication both at global and international levels in a country, is now an important part of our lives. However, not everyone has the opportunity to engage in intercultural interactions with people from different cultures [2]. In intercultural competence, Byram (1997) emphasizes that inter-cultural communication competencies (ICC) include several processes, including: the development of cultural knowledge that continues to develop rapidly, the skills of discovery and interaction with others and between cultures, have a critical awareness and open attitude. This open language means being prepared to accept cultural differences. In general it was concluded that formal foreign language teaching (L2) was not enough to be able to develop ICC students in schools [3]. 
Technology and the internet make people getting more immersive interaction and getting closer. By using synchronous communication tools, people can communicate using voice and video instantly, such as Skype to enhance the skills of discovery and interaction and open attitudes. Asynchronous communication tools such as e-mail, instant messages, blogs, wikis and so on, these tools assist people in sending a text or sharing any content which easily communicates and gets any information to improve cultural knowledge and critical awareness. Lately the development of the world is very fast, non-native speakers can easily access the original text, learn about intercultures and hear languages like those used in real-life situations by native speakers today have almost no difficulty [4].

In this first semester, we reviewed studies from 2014-2018 technology-enhanced intercultural model. We aimed to summarise the following eleven dimensions: Byram's model, technology used, learning environment, culture, language, number of participants, level of participants, learning activities and the topics. The reason why this study is important is mainly that there are not so many review studies on intercultural learning with technology-enhanced. One study by Çiftçi (2016) "A Review of Research on Intercultural Learning through Computer-Based Digital Technologies", He summarised th $\quad$ ies on intercultural learning supported by technology from 2004 to 2014 the focus is mo the fect of recent computer-based digital technologies and their effectiveness on intercultu

Our study of be an previous studies because of the following reasons. First, we review the recent studies p d o. 2014-2018. Second, we report technology-used, which either was not mentioned in earh revit stu s was mentioned before but never used after 2014. The rapid growth of technology ns so fac developing this technology, the vendors move for forwarding to make new technology and ovation it makes some technology more powerful, and some other technologies are ruled out. 2 , rd, we experienced educators and researchers with up-to-date research information on the applic of chnology-enhanced intercultural learning. Fourth, we provide a larger elaboration of thea description.

Here, we outlined some major qu ons for wer in this review study: What were Byram's models? What did the influences of techn and learning environment on Byram's models? How did the influences of cultures, languages, crent number and level of participants on Byram's models? What were the learning activities and pic to s of intercultural learning? What were the issues and the solutions? What were the recomn ndation or future study and practised?

\section{Method}

The method used to write this review followed previou atterns vork of [2] and Shadiev, Hwang, and Huang (2017). During collecting articles as main so s, used Google scholar, Baidu scholars, Science Direct and Mendeley search platform; we oo d suchkeywords as crosscultural learning, technology, intercultural learning, promoting, "qciltratin derstanding and competence to find articles. After getting the list of the articles accon ing eyw and then we applied some criterions for further screening: (1) the studies that were p ashed $g$ 2014-2018; (2) studies focused on intercultural learning supported by technology; (3) st lied dexed by Social Science Citation Index (SSCI) in Education and Educational Research category; (4) studies that were published as full text in the top nineteen journal related to educational technology, e.g. ReCALL (rank 46), Language Learning \& Technology (rank 47), and Computer Assisted Language Learning (rank 58). 


\section{Results and Discussion}

The Social Sciences Citation Index is a multidisciplinary index and indexes over 3,000 social sciences journals - 1988 to present. It is an important journal retrieval and paper reference channel with high authority in the field of social sciences. Table 1 illustrates studies during our work-inprogress, which were studies related to cross-cultural learning (CCL) and intercultural learning (IL).

Table 1. Studies during work-in-progress.

\begin{tabular}{|c|c|c|c|c|}
\hline No. & Authors & Title & CCL & IL \\
\hline 1 & [6] & $\begin{array}{l}\text { A study of the facilitation of cross-cultural } \\
\text { understanding and intercultural sensitivity using } \\
\text { speech-enabled language translation technology }\end{array}$ & $\sqrt{ }$ & \\
\hline 2 & [1] & $\begin{array}{l}\text { A study of learners' perceptions of online } \\
\text { intercultural exchange through Web } 2.0 \\
\text { technologies }\end{array}$ & & $\sqrt{ }$ \\
\hline 3 & & $\begin{array}{l}\text { egies for Smooth and Effective Cross } \\
\text { rral Online Collaborative Learning }\end{array}$ & $\sqrt{ }$ & \\
\hline 4 & [3] & $\begin{array}{l}\text { ook to Promote Korean EFL } \\
\text { rcultural Competence }\end{array}$ & & $\sqrt{ }$ \\
\hline 5 & [8] & $\begin{array}{l}\text { acilitating cross- } \\
\text { arning activity: }\end{array}$ & $\sqrt{ }$ & \\
\hline 6 & [9] & $\begin{array}{l}\text { Facilitating ciss atural inderstanding with } \\
\text { learning activities upported speech-to-text } \\
\text { recognition and computer-aide can lation }\end{array}$ & $\sqrt{ }$ & \\
\hline 7 & [10] & $\begin{array}{l}\text { A pilot study: Facili } \\
\text { understanding with project-bas } \\
\text { learning in an online environment }\end{array}$ & $\sqrt{ }$ & \\
\hline 8 & [4] & $\begin{array}{l}\text { Using an online collaborative projec twee } \\
\text { American and Chinese students to deve } \\
\text { teaching skills, cross-cultural awareness and } \\
\text { language skills }\end{array}$ & $\sqrt{ }$ & \\
\hline 9 & [11] & $\begin{array}{l}\text { Fostering Foreign Language Learning Through } \\
\text { Technology-Enhanced Intercultural Projects }\end{array}$ & & $\sqrt{ }$ \\
\hline 10 & [12] & $\begin{array}{l}\text { Promoting EFL learners' } \\
\text { communication effectiveness: a focus on } \\
\text { Facebook }\end{array}$ & & $\sqrt{ }$ \\
\hline
\end{tabular}

After screening the articles according to the above criterions, finally, four studies were selected to be a review related to intercultural learning. In this review, we firstly report and checked selected studies into tables and then reviewed the studies from the following six dimensions: (1) Byram's 
models, (2) influences of Byram's models on technology used and learning environment, (3) the influences of Byram's models on cultures, languages, different number and level of participants, (4) learning activities and the topics in terms of intercultural learning (5) issues and the solutions, (6) recommendation for the future study and practise.

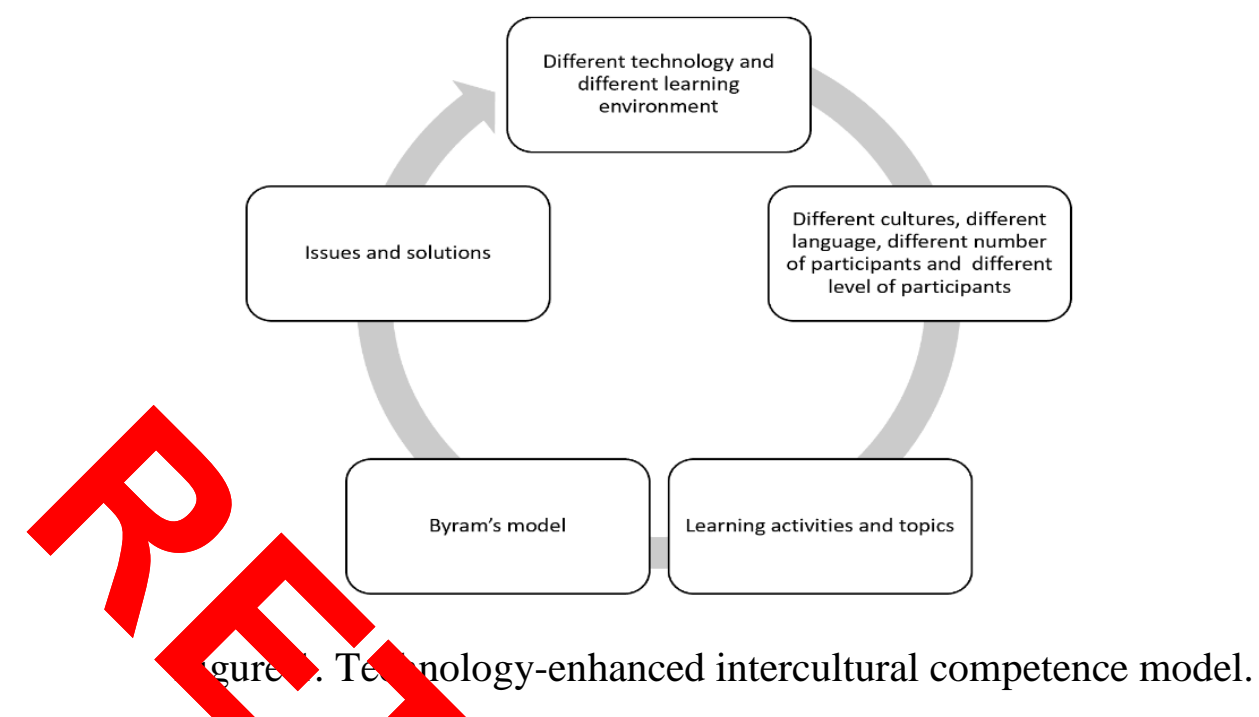

\subsection{Byram's Moden}

One way to describe in ridual tence in intercultural situations refers to ICC. Byram (1997) defines the ICC in his writ as basic ability of each to be able to communicate and interact across cultural boundar veloping intercultural (IC) foreign language students (FL) to make them agents of 'interc ural sperkers' as suggestions as a primary goal in FL education.

Byram (1997) explains that the moder o rcultural communication, suggests that students must obtain several things including: (1) "kno edg hich includes knowledge of the social sphere, practices, products, and interaction proces s, (2) titude ( A) "That is about curiosity, openness and ready to learn other cultures, (3)" in preting and lating skills (SIR) "namely skills to be able to explain and identify cultural perspec. nd med between them, (4)" Skills of discovery and interaction (SDI) "namely the skills to acquire $N \mathrm{~K}$.wledge and practices about culture and apply this knowledge in direct and tangible ommuni on, (5)" critical cultural awareness (CA) "which includes critical evaluation of pracíces, $p$ acts and their own cultural perspective with other cultures [12].

This model explains the main components of the IC and intercu al spe is bilities, such as: the knowledge, skills, attitudes, and perspectives they need in addition t nguist competencies, which serve as successful intercultural communication. This ICC mode an se as a good and appropriate reference and guideline used by teachers to teach and evaluate nits to develop IC learning.

\subsection{Influences of technology used and learning environment on Byram's model}

Most of the review studies did not use only one tool to support and facilitate intercultural interactions. To have a glimpse of what kind of technologies used and how the influences on Byram's model, in Table 1, below explain how the influences.

Table 2. Technology used

\begin{tabular}{lllllllll}
\hline \multirow{2}{*}{ No } & Technology & Frequency & \multirow{2}{*}{ Year } & \multicolumn{2}{c}{ Byram's model } & & \\
\cline { 5 - 8 } & & & & K & A & SIR & SDI & CA \\
\hline 1 & Facebook & 2 & 2015,2017 & $\sqrt{ }$ & $\sqrt{ }$ & $\sqrt{ }$ & $\sqrt{ }$ & $\sqrt{ }$
\end{tabular}




\begin{tabular}{lllllllll}
2 & Blogs & 2 & 2014 & - & $\sqrt{ }$ & $\sqrt{ }$ & - & $\sqrt{ }$ \\
3 & Podcasts & 1 & 2014 & $\sqrt{ }$ & $\sqrt{ }$ & $\sqrt{ }$ & $\sqrt{ }$ & $\sqrt{ }$ \\
4 & Twitter & 1 & 2014 & $\sqrt{ }$ & - & $\sqrt{ }$ & - & $\sqrt{ }$ \\
5 & e-mail & 2 & 2014,2016 & $\sqrt{ }$ & $\sqrt{ }$ & $\sqrt{ }$ & $\sqrt{ }$ & $\sqrt{ }$ \\
6 & Blackboard & 1 & 2014,2016 & $\sqrt{ }$ & - & - & - & - \\
7 & Moodle & 1 & 2014 & - & $\sqrt{ }$ & $\sqrt{ }$ & $\sqrt{ }$ & - \\
8 & iMovie and Movie Maker & 1 & 2014 & $\sqrt{ }$ & - & - & - & - \\
9 & online forum & 1 & 2014 & $\sqrt{ }$ & $\sqrt{ }$ & $\sqrt{ }$ & $\sqrt{ }$ & $\sqrt{ }$ \\
10 & Skype & 1 & 2014,2016 & $\sqrt{ }$ & $\sqrt{ }$ & $\sqrt{ }$ & $\sqrt{ }$ & $\sqrt{ }$ \\
\hline
\end{tabular}

As we can se from the table, there are eleven tools in the literature. Among these technologies, e-mail, Facel k, Blogs were mostly used. The technologies used only once were Podcasts, Twitter, S1 o, Moo e, iMovie and Movie Maker, and the online forum. These technical tools were used in thrs res wi ded into synchronous communication tools (Skype) and asynchronous communicatio ols ce. ok, Blogs, Podcasts, Twitter, e-mail, Blackboard, Moodle, iMovie and Movie Maker, and at forum in intercultural learning.

The influences o. 'chnology Byram's model can be shown that to reach (1) knowledge can be utilized Facebook, Wdcast $\hat{w}$ er, e-mail, Blackboard, Moodle, iMovie and Movie Maker, online forum, and Skype. To ach (2) itudes can be utilized, Facebook, Podcasts, Blogs, e-mail, Moodle, online forum, and skype. $T$ eas (3) skills of interpreting and relating can be utilized email, Facebook, Blogs, Blackboa o pe odcasts, Twitter, Moodle, and online forum. To reach (4) skills of discovery and interaction an be used utilized e-mail, Facebook, Skype, Podcasts, Moodle, and online forum. To reach (ritical al awareness can be utilized e-mail, Facebook, Blogs, Skype, Podcasts, Twitter, and onlin un

In 2014 researchers begun the study and th zed hronous tools. In the subsequent of the study, authors began to utilize and combine nc onous d synchronous tool to create a more immersive learning environment. By utilizing oth th crmbination of asynchronous and synchronous communication tool, intercultural lea ing becomes ore worthful. In addition, we found that studies during 2004-2014 [2], there are som hew to gies used such as Facebook, Blackboard, Skype, Twitter, Moodle, iMovie and Movie raker; the other hand, some communication mentioned no longer used on the previous view to a $\mathrm{p}_{\mathrm{t}} \mathrm{rt}$ intercultural learning such as online message board and text-based chat. By rapid grow tech, ology and the need of global society to interact with people around the world, so mo po ful and efficient technology will be created in future to make the intercultural learn envi mo more effective and more impressed such Hologram, VR technology, Artificial Intelligent sud, et

\subsection{Influences of cultures, languages, number and level of participan}

In the literature, studies were conducted with different participants from a different country, at least two different countries and culture involved. All of the studies took place on online platforms. [1] reports a Spanish-American tele collaborative project intercultural exchange online viewing and exchange of students as an extraordinary place for intercultural communication with native speakers, through social engagement, students not only gain cultural knowledge but also become more aware of their own attitudes towards their own culture [3]. The results can be concluded that Facebook offers EFL Korea students an effective and efficient platform for intercultural interaction with people from the intended local culture, and EFL Korean students demonstrate the overall component capabilities of the IC [11]. This project is designed to improve language skills to students and intercultural communication skills (ICC) [12]. Facebook provides opportunities for students to be able to learn about other cultures through several features such as walls, group discussions, video sharing, and chatting features. 
Regarding the languages, different number and level of participants in these studies, Spanish $(n=1)$ and English $(n=4)$. [1] this study involved 28 participants, 10 participants were American participants, and 18 students were Spanish students, the participants level were postgraduate and undergraduate. [3] this study involved 52 participants, 32 participants were Korean, and 20 participants were American, the participants level were undergraduate students with age range 19 to 22 years old. [11] this study involved 15 Taiwanese participants and the level of the participants was junior high school. [12] this study involved 40 participants and the level of participants was undergraduate. Figure 2 below illustrates the cultures, languages, number and level of participants.

Table 3. Language, number and level

\begin{tabular}{llcll}
\hline References & Language & Number & \multicolumn{1}{c}{ Level } \\
\hline$[1]$ & Spanish & 28 & Graduate and undergraduate \\
& English & 52 & Undergraduate \\
& English & 15 & Junior high school \\
& English & 40 & Undergraduate
\end{tabular}

As for the language in is stud a aggested to use another language as language communication such as Chinese or another i nation oreign language. Most participants, according the studies, were 52 participants, and the lowes as participants, it is always be suggested to utilize more participants to reach different le res in intercultural learning. The level that we can see above mostly the undergraduate level o ruticipants and only one study researched the junior high school level. It is always suggested differen earch participants such as senior high school, elementary school, and so on.

\subsection{The learning activities and the topics in cer of int cultural learning}

According to the result, we can summarize the attern of le ing activities and topics on the studies on the table below.

\begin{tabular}{cl} 
References & Table 4. Learning activitie Activities \\
\hline [1] & Getting to know each other, \\
& exchanging cultural perspectives, and das life. \\
& discussing controversial issues. \\
& Promote discussion, choose a topic Culture differences. \\
& for discussion and reflecting \\
& interview. \\
& Storytelling, video conference, Folk tales, traditional story, custom \\
& email exchange. \\
& Assigning participants randomly in Culture, identity, gender roles, \\
& two groups, administration of the speech communities, language, \\
& background questionnaire and IES, communication, physical space (the \\
& intercultural instruction and perception of time), definition,
\end{tabular}


discussions, Re-administration of stages, and Stereotyping.

the IES, interviews and essays.

As we can see above, the activities on the studies generally created such patterns as follow, (1) introduction, (2) pairing students, (3) choose topic, (4) exchanging culture, (5), reading lesson and writing essay (6) video conference, (7) e-mail exchange, and (8) interviews. The topics mostly utilized on the studies were culture $(n=4)$, daily life $(n=2)$, controversial issues, language, communication, physical space (the perception of time), definition, stages, and Stereotyping.

\subsection{The issues and the solutions}

Here we showed the issues and solution to the studies during our work-in-progress.

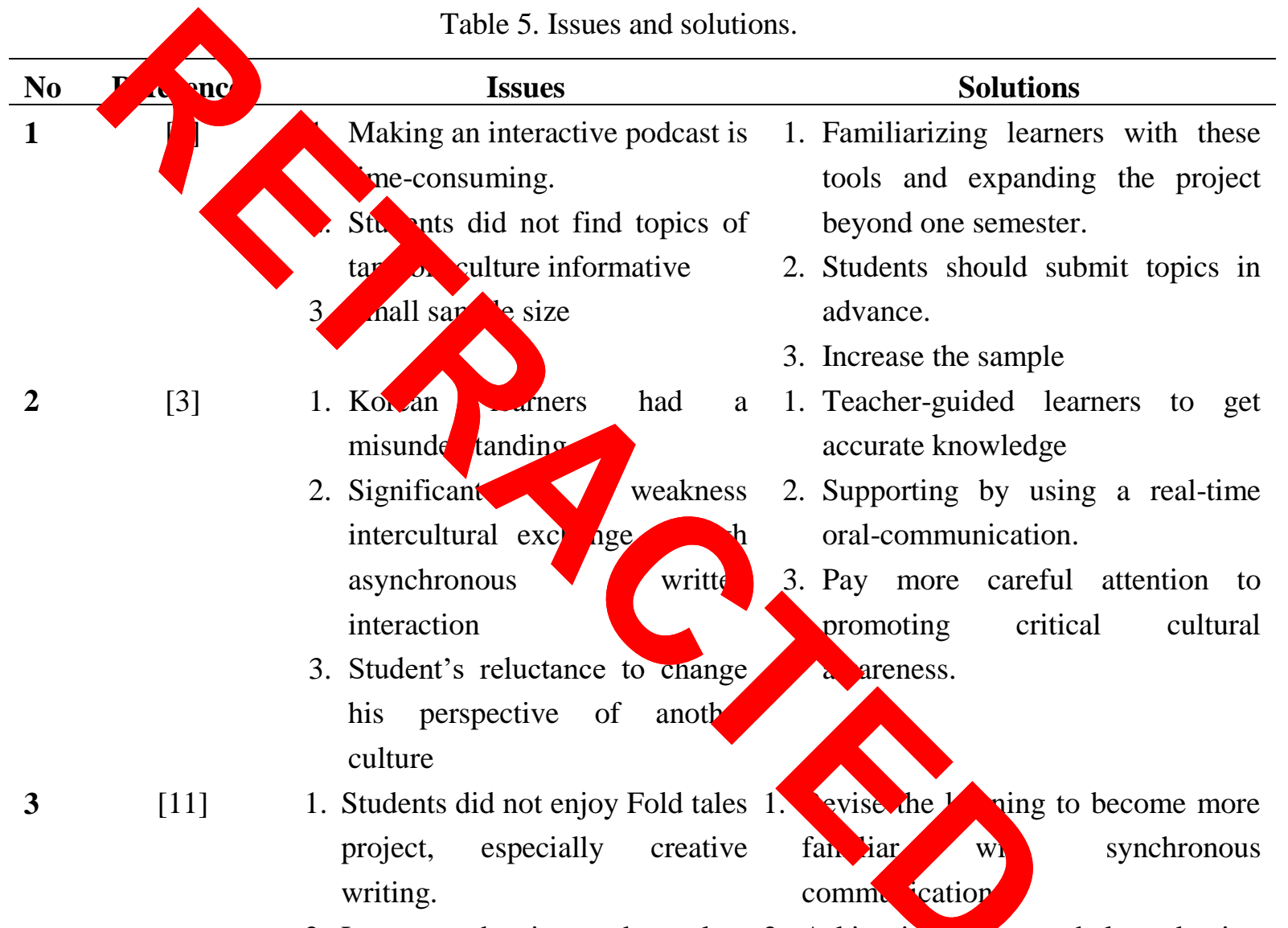

2. Language barrier such as low 2. Asking insuctors to help and using vocabulary. translator tools such as STR and CAT [8]

[12] 1. Two students said rarely using 1. I am improving students' skills of Facebook and preferred to use discovery and interaction to make a other tools.

2. Some of the students expressed interesting for students.

their fears about using Facebook 2. I was examining as this appeared to for educational purposes. be a problem in terms of using Facebook. 
As we can see above, each study had two to three issues. The most issues that mostly we found here were familiarization $(n=3)$ such as making an interactive podcast is a time consuming, students did not enjoy Fold tales project especially creative writing, and two students said rarely using Facebook and preferred to use other tools. Solutions given for these issues were familiarizing learners with these tools, revise the learning to become more familiar with synchronous communication, and improving students' skills of discovery and interaction to make a discussion on Facebook more interesting for students.

This explanation and discussion offers several important recommendations for anyone who intends to use technology in terms of intercultural learning. First of all, the overall picture of this literature (Figure 1) has pushed this review to the most important necessities. One of the is familiarization on technology tools both synchronous and asynchronous tool to bring the learning activities more active, avoid the fear of participants and avoid the misunderstanding between instructors to learners and learners to the learner.

Secondly, training participants is not sufficient for successful interaction and communication during intercult learning. A stimulating learning environment must be created to simultaneously motivate and gago arning. The motivating and engaging learner can be utilized the most updated technolog an see now, young people mostly engage with Instagram, Instagram is the most trending so 71 net for teens aged 15-22 years old (www.lifewire.com, 2018).

Finally, in turm ach il of IC's components, the author should utilize various projects to help students to re. the vel o. 'C. A study by [3] reaches five keycomponents of IC (knowledge, attitudes, skills of erpreting relating, skills of discovery and interaction and cultural awareness). Next to future stur shourd focus on how to reach these five levels to give learners more depth learning activities. W alize th review has several limitations. Firstly, articles reviewed in this study mostly were not high e.g ReCALL (rank 46), Language Learning \& Technology (rank 47), and Computer Assis Là Learning (rank 58) on rank of SSCI, Journal Data Filtered By Selected JCR Year: 2017 ected Editions: SSCI Selected Categories: 'EDUCATION \& EDUCATIONAL RESEARCH' So cted $y$ Scheme. The number of reviewed articles in review only four articles. Finally, we ain fi current guideline in the year of 2018-2019; this review follows the guideline by the previous delin and [2]. As this is a work-in-progress study, we aim to complete the review of more mp unsio shortly.

This review on online intercultural learning is ell posit. on since it has revealed a sufficient number of issues to be considered [2]. Here, we cal say th ur review consists of Byram's models, influences of technology used and learning environ at a Byram's models, cultures, languages, different number, level of participants, learni activit the topics in terms of intercultural learning, issues, solutions, recommendations formuture y a

We discovered some following finding during our reviews pro ded $\wedge$ me suggestion for future research and development. Firstly, people who want to conct the s? arch interest as intercultural learning must pay serious attention to how to reach five wom dents \& Byram' model (1997) about intercultural competence (IC). IC components are the mos tal in ator to say that intercultural learning, according to Byram's model, reaches successfulness.

Technology-used should fulfil the today need of the learner. Combination of asynchronous and synchronous communication is mostly suggested for the next future research. We also believe by the need of global society and the rapid growth of technology, people around the world need more advanced technology such as Hologram, VR technology, artificial intelligent features, cloud and so on. This does not close the chance for near future research to research more powerful technology to support intercultural learning. Most of the articles we reviewed correlated with two culture, we hope in the future that will be more culture involved. We are also planning to work in another review, such as a review on cross-cultural learning.

We also discovered mostly language used in this research was English and Spanish. IC can be developed by foreign language in special or in common language. In this context, we still can consider another foreign language such as Chinese, Russian, Germany and others. We also can broader our future research by enlarging the number of participants to make a more depth study in research and development and by utilizing the different level of participants such as college students, senior high school, elementary school, kindergarten and so on to get richer study comprehension. 
In additional to elaborate the learning activities and the topics, we also discovered that learning activities in the intercultural learning activities showed various components of learning activities as follow: (1) introduction, (2) pairing students, (3) choose topic, (4) exchanging culture, (5), reading lesson and writing essay (6) video conference, (7) e-mail exchange, and (8) interviews. Most of the topics mentioned above were culture and daily life; we suggested the near future research to enrich the learning topics on intercultural learning such as how to get more authentic and more immersive intercultural learning by outdoor online intercultural learning.

Finally, we find some issues, solution and suggestions for future study and practise. The most issues that mostly we found here were familiarisation. Solutions given for these issues were familiarizing learners with these communication tools.

\section{Conclusion}

The result from this research is (1) This ICC model can be used as a good reference and guideline for teasher planning in discussions and discussions to develop IC students. (2) Intercultural learni more effective and more impressive such as Holograms, VR technology, Artificial In geno cloud, etc. (3) The most widely used topics in the studio are culture $(n=4)$, daily life $=2 \quad$ royersial issues, language, communication, physical space (time resolution), resolution, resol on, tereotyping. (4) Problems, solutions, and suggestions for future studies and practices. ast e p lems that most of us find here are socialisation. The solution to this problem is to fam ase dent with this communication tool.

Acknowledgement

This paper can be comp a becay of the support and assistance of many parties. Thank you very much to my supervisor and Education.

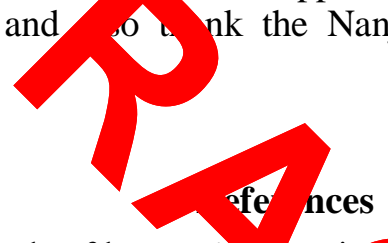

[1] L. Lee and A. Markey, "A study of learners' cept online intercultural exchange through Web 2.0 technologies," ReCALL, vol. 26, no. 3, pp 81,201

[2] E. Y. Çiftçi, "A Review of Research on Inter Itural Learm through Computer-Based Digital Technologies Research methods," vol. 19, pp. 313-- 16.

[3] S. Jin, "Action Research Using Facebook To Promote Korear M Learne Intercultural Competence," Lang. Learn. Technol., vol. 19, no. 3, pp. 38-51, 2015.

[4] M. Angelova and Y. Zhao, "Using an online collaborative pre to be sherican and Chinese students to develop ESL teaching skills, cross-cultural awareness at anguag Lang. Learn., vol. 29, no. 1, pp. 167-185, 2016.

[5] R. Shadiev, W. Hwang, and Y. Huang, "Review of research on mobile lan age ning in authentic environments," vol. 30, pp. 284-303, 2017.

[6] R. Shadiev, A. Sun, and Y.-M. Huang, "A study of the facilitation of cross-cultural understanding and intercultural sensitivity using speech-enabled language translation technology," Br. J. Educ. Technol., vol. 00, no. 00, pp. 1-19, 2018.

[7] J. Yang, H. Yu, S. Chen, and R. Huang, "Strategies for Smooth and Effective Cross-Cultural Online Collaborative Lea...: NU Library Collection," vol. 17, pp. 208-221, 2014.

[8] R. Shadiev, T. T. Wu, A. Sun, and Y. M. Huang, "Applications of speech-to-text recognition and computer-aided translation for facilitating cross-cultural learning through a learning activity: issues and their solutions," Educ. Technol. Res. Dev., vol. 66, no. 1, pp. 191-214, 2018.

[9] R. Shadiev and Y. M. Huang, "Facilitating cross-cultural understanding with learning activities supported by speech-to-text recognition and computer-aided translation," Comput. Educ., vol. 98, pp. 130-141, 2016.

[10] R. Shadiev, W. Y. Hwang, and Y. M. Huang, "A pilot study: Facilitating cross-cultural understanding 
with project-based collaborative learning in an online environment," Australas. J. Educ. Technol., vol. 31, no. 2, pp. 123-139, 2015.

[11] J. J. Chen and S. C. Yang, “Technology-Enhanced Intercultural Projects,” Lang. Learn. Technol., vol. 18, no. 1, pp. 57-75, 2014.

[12] E. Özdemir, "Promoting EFL learners' intercultural communication effectiveness: a focus on Facebook," Comput. Assist. Lang. Learn., vol. 30, no. 6, pp. 510-528, 2017.

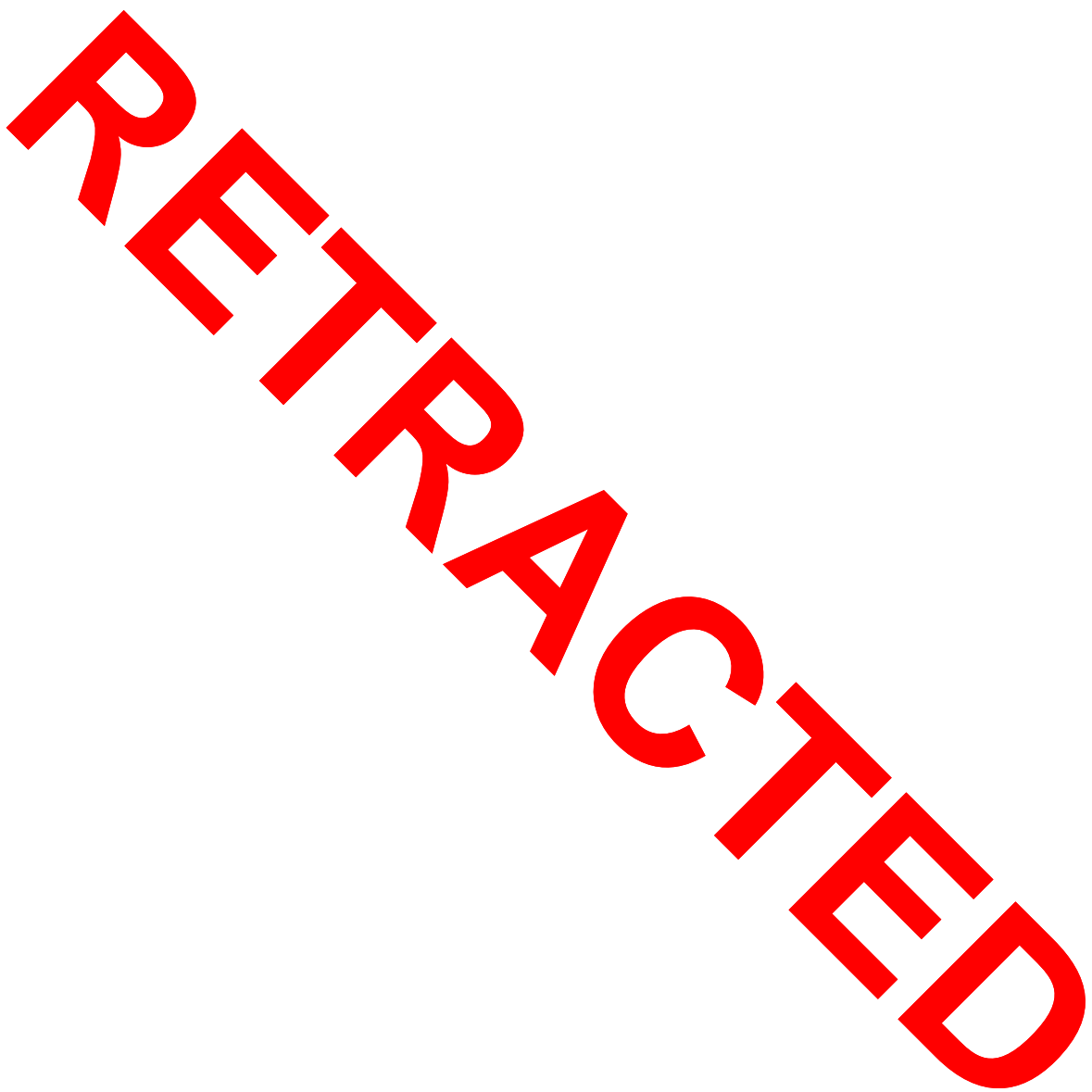

